\title{
The use of geographical data and information in retail locational planning
}

\author{
RECEIVED: 25 SEPTEMBER, 2000
}

J. W. Byrom,* D. J. Bennison, T. Hernández and P. D. Hooper

*Locational Planning and Marketing Group, Department of Retailing and Marketing, The Manchester Metropolitan University Business School, Aytoun Street, Manchester MI 3GH Tel: (+44) $016 I 247$ 6064; Fax: (+44) 0161247 6305; e-mail: j.w.byrom@mmu.ac.uk

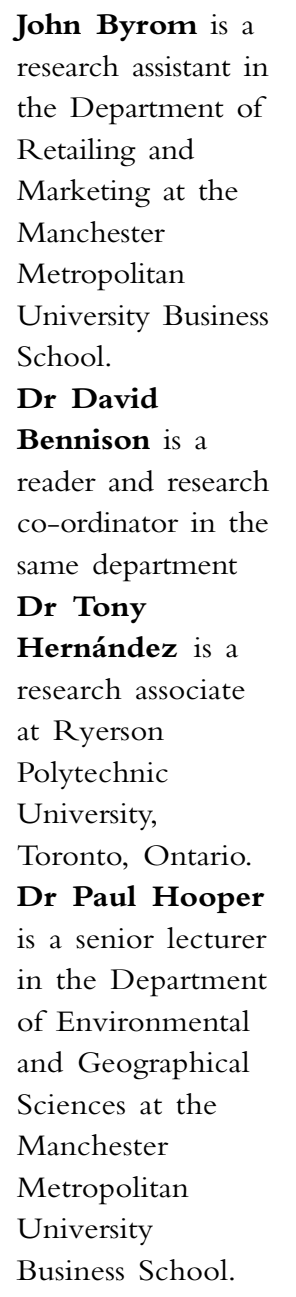

John Byrom is a

Abstract

As the supply of suitable sites for retail development in the UK becomes ever more rare, location analysts are increasingly recognising the need to become more innovative in terms of their locational strategies. Although the role of intuition in locational decision making is still an important one, the advent of new methods and technologies, including neural networks and geographical information systems (GIS) are increasingly impinging on existing locational practices.

It becomes clear that if new methods for locational planning are to make a return on the large investments that have been employed in them, detailed knowledge and innovative use of data and information is required. A significant element of these data and information is the geographical one, given that almost all data can be classed as 'geographical', that is 'they contain a reference to an address on the surface of the Earth'. Manipulation and awareness of the geographical nature of data can hold many benefits for locational decision making, beyond the basic mapping of store locations.

This paper presents the results of a large-scale postal survey carried out among retail locational decision makers in UK retailing. The survey audited the collection, use and applications of data and information. The use of geographic information (GI) was investigated and it was found that while locational decision makers were becoming more adept at using data and information, the geographical dimension was still somewhat latent.

\section{INTRODUCTION}

UK retailing has been characterised by heightened competition in certain sectors in recent years. This, combined with government policy seeking to discourage the development of retail stores in off-centre locations, ${ }^{1}$ concerns over saturation in some sectors, ${ }^{2,3,4}$ and the (potential) threats posed by shopping over the Internet, ${ }^{5,6}$ have meant that a number of store-based retailers have recognised the importance of locational planning practices. Whereas previously locational decisions were often based largely on intuition, ${ }^{7}$ it is now the case that more considered approaches to planning and managing the locations of retail outlets are becoming apparent. ${ }^{8}$ These include the use of more advanced techniques and 


\section{Table 1}

\section{THE 6 RS OF THE LOCATION MIX}

\section{Type of Decision Description}

\begin{tabular}{|c|c|}
\hline Roll-out & Increasing floor space in existing store or opening a new store \\
\hline Relocation & $\begin{array}{l}\text { Moving to a new site due to close proximity of two stores, or } \\
\text { availability of a new retail pitch }\end{array}$ \\
\hline Rationalisation & Closure of individual stores, or selling of divisions \\
\hline Refascia & Altering image of outlets by changing their name/appearance \\
\hline Refurbishment & Updating fittings \\
\hline Remerchandising & $\begin{array}{l}\text { Altering product range of a retail location, tailoring offer to the local } \\
\text { consumer }\end{array}$ \\
\hline
\end{tabular}

technologies such as neural networks and geographical information systems (GIS) in the planning and management of the store portfolio." Despite the introduction of such technologies in a number of locational planning departments, it is clear that human judgment is still a vital part of locational decision making and indeed that 'location decision making is likely to always remain both an "art" and "science", ${ }^{10}$

The traditional concern of practitioners and academics with the opening or 'roll-out' of new stores has, over the course of the last decade, been challenged by recognition of the significance of managing other aspects of the store portfolio. The rationalisation of outlet networks became apparent in some sectors, especially, for example, the financial one, ${ }^{11}$ and the importance of other types of loca- tional decision were also acknowledged. These decisions include the 'refasciaing' and remerchandising of outlets according to the composition of local markets, and recognition of the need to relocate and refurbish existing outlets. ${ }^{12,13}$ The so-called ' $6 \mathrm{Rs}$ of the location mix' displayed in Table $1^{14}$ demonstrate the various decisions that have become increasingly important to locational decision makers.

Against this backdrop of a widened scope to locational decision making there has been a significant increase in the data available to support locational decision making. This has occurred in part through the large amounts of data that are now gathered via scanning technologies such as electronic point of sale $(\mathrm{EPoS}),{ }^{15}$ and through loyalty card transactions. ${ }^{16}$ Also available to the locational planner are a number of potentially powerful commercial life- 
style and geodemographic databases ${ }^{17}$ which contain detailed information on the habits and locations of customers. Maximising the use of data in locational planning activities remains a key challenge for decision makers if the returns invested in such sources are to be realised. Clearly at issue is the ability of decision makers to turn their sheer quantities of data into information, namely 'data with meaning'. Earlier work published in this Journal has considered the role of data specifically in the context of the development and diffusion of GIS, ${ }^{18}$ yet there has been little, if any, recent work which has focused principally on the geographic nature of data and information and its role in the retail locational decision.

A significant dimension to many of these data and information sources is the geographical one. Geographical information (GI) is defined as information which can be referenced to specific locations on the Earth', ${ }^{19}$ and it has been argued that some 90 per cent of all commercial sources of data are geographic in nature. ${ }^{20}$ Recognition of the geographic dimension to data can result in, inter alia, the mapping of store networks and the distribution of customers, both of which are valuable applications in retail locational planning. Despite the prevalence of a geographic dimension in data, exploratory research has suggested that practitioners' awareness and their subsequent uses of this feature of their data are at present lacking. ${ }^{21}$ In order to assess the current use of (geographic) data and information in retail locational planning, a postal questionnaire was devised and distributed.

\section{METHODOLOGY}

The questionnaire was targeted principally at multiple retailers operating over 50 outlets with the sample constructed using commercially available directories..$^{22,23}$ In total, 289 questionnaires were distributed to individuals responsible for store locational planning or property management with names being gathered via a prior telephone call. This enabled questionnaires to be posted to a named individual, thereby potentially increasing the response rate. ${ }^{24}$ The questionnaire was presented in a 12-page A4 format and contained a mixture of closed and open-ended questions. A covering letter was also included as was a promise of complementary summary findings for respondents, both of which are established research strategies for inducing responses. ${ }^{25} \mathrm{~A}$ pre-paid return envelope was included as well as these too are thought to increase response rate. ${ }^{26}$ Analysis of the responses was carried out using the Statistical Package for the Social Sciences (SPSS) ${ }^{27}$ and basic contenttype analysis where appropriate. ${ }^{28}$ In total, some 104 respondents returned the completed questionnaire, a response rate of 36 per cent, greater than Saunders et al's marker of 30 per cent as a 'reasonable' response through this medium. ${ }^{29}$ A further 11 per cent of respondents declined to take part in 
Table 2

SURVEY SAMPLE BY NUMBER OF OUTLETS OPERATED

Number of outlets

50 or less

51-100

$101-250$

251-500

501-1,000

$1,001-2,500$

Over 2,500
$\%$ of sample

5

13

37

21

13

8

3 the survey for reasons such as pressures of time and commercial sensitivity.

\section{DISCUSSION OF RESULTS}

The paper now turns to discuss some preliminary results from the questionnaire survey and, in particular, to illustrate the current state of retail locational planning with respect to decision makers' use of data and information. The 36 per cent of respondents that replied to the questionnaire were responsible for the operation of some 49,000 outlets in total, with the breakdown by number of outlets given in Table 2. Respondents were drawn from a number of retail sectors including grocery, financial, fashion and pub/off licence.

\section{Use of data and access to data}

The vast majority of respondents (95 per cent) collected data, with the average number of data sets collected being ten. Table 3 shows the percentage of respondents collecting named data sets, divided between internal and external sources of data. As can be seen, a number of data sets with common features are more frequently collected. Census data, geodemographic data and lifestyle data were gathered from external sources by roughly two-thirds of respondents. In terms of data collected from within the organisation, competitor, customer transactional and operational data predominated.

The sharing of data within retail organisations is an important aspect for decision makers if duplication of effort and increased costs within retail organisations are to be avoided and the use of data sources is to be maximised. To that end, part of the questionnaire included a section on the sharing of data and access to data. It was found 
Table 3

PERCENTAGE OF RESPONDENTS COLLECTING NAMED DATA SETS

\begin{tabular}{llll}
\hline \multicolumn{1}{c}{ Internal sources } & External sources & \multicolumn{1}{c}{ \% of } \\
Data set & sample & Data set & sample \\
Competitor & 81 & Geodemographics & 72 \\
Market research & 70 & Census & 70 \\
Store operations & 65 & Lifestyle & 58 \\
Customer transaction & 64 & Shopping centre & 55 \\
Store space planning & 59 & Planning applications & 43 \\
Shopping centre & 53 & Other central government & 41 \\
Loyalty card & 31 & Shopping survey & 39 \\
Customer after sales & 15 & Traffic & 38 \\
Other internal & 6 & Audit (product) & 22 \\
& & Psychodemographic & 16 \\
& & Other external & 2 \\
\hline
\end{tabular}

that some 86 per cent of respondents shared data within the company with six datasets on average being shared. Table 4 shows which data sets were shared most frequently, as a proportion of those respondents collecting the specified data set. From this, it is clear that internal data sets are more likely to be shared than external data sets. This may be due to the existence of dedicated systems for sharing internal data. Of those sharing data, some 57 per cent of respondents shared data with a single department more than any other.

Access to data was an important issue with respect to some respondents' priorities for improved sources of data and information, with the availability of data on the Internet or an intranet, or in a central data warehouse cited as being a requirement. The following quotes illustrate the need among some respondents for improved access to data and education as to what sources are available for use in locational decision making:

'We are not aware of what data and information is available. We need to know more.'

'Better education of other departments as to what's available is needed along with better software delivery systems, ie Internet/intranet mapping packages.' 
Table 4

PERCENTAGE OF RESPONDENTS SHARING NAMED DATA SETS

\begin{tabular}{llll}
\hline \multicolumn{1}{c}{ Internal data sets } & \multicolumn{2}{c}{ External data sets } \\
& $\%$ of & & $\%$ of \\
Data set & sample & Data set & \\
& & & 61 \\
Loyalty card & 88 & Census & 61 \\
Customer after sales & 88 & Geodemographic & 59 \\
Market research & 84 & Shopping survey & 56 \\
Store operations & 76 & Planning applications & 51 \\
Customer transaction & 75 & Lifestyle & 49 \\
Store space planning & 72 & Background map & 47 \\
Competitor & 68 & Shopping centre & 46 \\
Shopping centre & 45 & Traffic & 40 \\
& & Central government & 30
\end{tabular}

'Improved lines of communication between all departments would be good.'

Attitudinal statements were also a feature of the survey and from these it became clear that the amount of data available to respondents had increased in recent years: 74 per cent of respondents disagreed with the statement 'the amount of data at our disposal has not increased significantly in recent years'. In spite of this, just over half the respondents disagreed with the statement 'it often seems that we have too much data for our requirements'. Perhaps in support of the issue of access to data, it appears that even with a strong increase in data available, locational decision makers still feel that they are not yet maximising the use of this resource in their planning activities.

\section{Geographic data and information}

The main focus of the survey was to analyse the role of geographic data and information in retail locational decision making. One of the key determinants in the use of GI is the presence of appropriate technologies such as GIS to handle them. There was evidence that GIS were being implemented within locational planning departments with 45 per cent of respondents agreeing with the statement 'GIS are a vital part of our department's decision making processes'. In terms of awareness of the geographical nature of data and information, few respondents thought that 90 per cent of 
their internal sources of data were geographic in nature, as postulated by Moloney et al. ${ }^{30}$ Rather, the average figure given was 47 per cent, with those that had implemented GIS being generally more 'geographically aware' than non-implementers. This was evidenced by the fact that 57 per cent of GIS implementers' databases were stated to be geographic in nature as compared to 38 per cent of non-implementers' databases. The presence of geographic technologies can serve to highlight the geographical nature of data and information.

Some 85 per cent of respondents felt that the geographic referencing to data was either 'very important' or 'quite important' to their company, suggesting that practitioners could see the value in knowing and applying the locations of customers and outlets in space. In contrast to the importance placed on GI, 47 per cent of respondents stated that they were not maximising the use of this resource. Respondents thought that the use of geographic data could be improved in a number of ways, including:

'having the time to spend studying the data'

'the greater use of customer data'

'knowing more about competitor locations/sizes so that strategy planning can be better performed'.

The attitudinal statements (Table 5) also highlighted the fact that geographic data are an important resource to many locational planning executives.

An apparent increase in the amount of technology available for store location decisions had resulted in most respondents holding data sets digitally - on average some 56 per cent were held in this format, with 23 per cent of these reportedly held in a GIS. In terms of geographic scales that were used, postal geography units predominated, with 60 per cent of respondents using this format, followed by company specific regions or areas, such as store catchment areas, which were used by half of all respondents.

\section{Locational decision-making}

A central aim of the survey was to assess current locational decisionmaking practices and strategies and the role of data and information therein. Most respondents (74 per cent) stated that the number of outlets they operated had increased in the last five years. Some interesting intersectoral differences were apparent, however, when respondents' views on how the number of outlets would change in the next five years were sought. Overall, 67 per cent of respondents thought that the number of outlets they operate would increase, but this average masks considerable intersectoral variations. While three-quarters of the grocery retailers thought their store networks would increase, just one of the financial sector respondents envisaged an increase in their branch networks.

Respondents reported a fair degree 
Table 5

\section{ATTITUDINAL STATEMENTS: GEOGRAPHICAL DATA ISSUES}

\begin{tabular}{llll}
\hline Statement & $\begin{array}{l}\text { Agree } \\
\%\end{array}$ & $\begin{array}{l}\text { Neither } \\
\%\end{array}$ & $\begin{array}{l}\text { Disagree } \\
\%\end{array}$ \\
$\begin{array}{l}\text { 'Geographic data are the key to many of our business } \\
\text { requirements' } \\
\text { 'Geographic data are unlikely to increase in importance }\end{array}$ & 68 & 27 & 5 \\
$\begin{array}{l}\text { over the next } 5 \text { years' } \\
\text { 'Awareness of the geographic element of data is } \\
\text { prevalent across our department. } \\
\text { 'Geographic data are no different from any other type } \\
\text { of data.' }\end{array}$ & 63 & 19 & 19 \\
\hline
\end{tabular}

of sophistication with respect to locational applications, such as targeting direct mail, monitoring outlet performance, and catchment area identification, that were utilised. The average number of named applications undertaken on an ad hoc basis was four and the average number of named applications carried out on a regular basis was six. Table 6 shows that in terms of applications undertaken on a regular basis, catchment area identification, site screening and the monitoring of outlet performance were carried out most frequently. Respondents operating more outlets tended to make use of more applications, suggesting that larger store networks necessitate greater investment and sophistication in locational techniques and applications.

In spite of the relatively large number of applications that were carried out by respondents, it was also clear that more traditional methods of site assessment were still a vital part of locational decision making: 96 per cent of respondents agreed with the statement 'making visits to potential and existing outlets is a vital part of our locational decision-making processes'. This suggests that despite rapid advances in the amount of technology available in recent years, intuition and a good 'retail nose' are still an essential part of locational decision making, as illustrated by the following quotes:

'Gut feel and experience has worked very well so far.'

'Locational identification still works predominantly on hunches and intuition. GIS is helping but not as fully as possible.' 
Table 6

PERCENTAGE OF RESPONDENTS UNDERTAKING LOCATIONAL APPLICATIONS ON A REGULAR BASIS

Application

$\%$ of sample

Catchment area identification

Site screening and selection

Monitoring outlet performance

Competitor analysis

Setting sales targets

Acquisition and merger planning $\quad 39$

Market mapping $\quad 31$

Store portfolio segmentation and planning 31

Network planning $\quad 29$

Customer profiling 26

Cannibalisation $\quad 25$

$\begin{array}{ll}\text { Merchandising mix analysis } & 20\end{array}$

$\begin{array}{ll}\text { Promotional/media analysis } & 20\end{array}$

Customer database planning $\quad 13$

$\begin{array}{ll}\text { Logistics planning } & 13\end{array}$

Targeting direct mail 13

'In my opinion, sound locational decision making is an art not a science. Without an understanding of the strengths and weaknesses of the base data ... geographic information and software is dangerous and costly witchcraft.'

Many respondents also stated that their locational decision-making processes were constrained by internal politics and bureaucratic decision-making structures, insufficient resources and a lack of appropriate data and information for decision making.

\section{CONCLUSIONS}

From the results discussed here, it becomes evident that on the whole there is relatively widespread collection and usage of data for use in retail locational planning. A number of different data sets were collected by retailers, but clearly at issue is the degree to which these data sets are used in locational decision making and in which applications. Answering such questions is difficult through the medium of a postal questionnaire although some tentative conclusions can be drawn here. The significant 
presence of data and information in the majority of locational planning departments suggests an increased level of innovation in terms of the processes of locational planning activity, with data and information becoming more systematically utilised in decision making. This contrasts with a previous era when intuition alone often governed the planning of new retail outlets. Also evident is the systematic use of a number of locational planning applications on both a regular and an ad hoc basis. In spite of the large amounts of data and information present in locational planning departments, it is also obvious that in the majority of cases, the geographic dimension is still somewhat latent. This survey has sought to assess the current role and significance of geographic information in UK retail locational planning. It is envisaged that subsequent research will seek to address further the role of geographic information and data in the retail locational decision making process, through an analysis and examination of the use and visualisation of GI by stakeholders in a number of case study organisations. This will enable greater understanding of the dynamics of retail locational decision making, which is particularly relevant in light of the continued significance of such decisions.

\section{REFERENCES}

1 Wrigley, N. (1998) 'PPG6 and the contemporary food store development dynamic', British Food Journal, Vol. 100, No. 4, pp. 154-161.
2 Guy, C. M. (1994) 'Grocery store saturation: Has it arrived yet?', International Journal of Retail \& Distribution Management, Vol. 22, No. 1, pp. 3-11.

3 Guy, C. M. (1996) 'Grocery store saturation: The debate continues', International Journal of Retail \& Distribution Management, Vol. 24, No. 6, pp. 3-10.

4 Langston, P., Clark, G. P. and Clarke, D. B. (1997) 'Retail saturation, retail location and retail competition: An analysis of British grocery retailing, Environment and Planning A, Vol. 29, pp. $77-104$.

5 Jones, K. and Biasiotto, M. (1999) 'Internet retailing: Current hype or future reality?', The International Review of Retail, Distribution and Consumer Research, Vol. 9, No. 1, pp. 69-79.

6 Rowley, J. (1996) 'Retailing and shopping on the Internet', International Journal of Retail \& Distribution Management, Vol. 24, No. 3, pp. 26-37.

7 Rogers, D. S. (1987) 'Shop location analysis' in McFadyen, E. (ed.) 'The changing face of British retailing', Newman, London, pp. 74-83.

8 Hernández, T. and Bennison, D. (2000) 'The art and science of retail location decisions', International Journal of Retail \& Distribution Management, Vol. 28, No. 8, pp. 357-367.

9 Hernández, J. A. (1998) 'The role of Geographical Information Systems within retail location decision making', unpublished $\mathrm{PhD}$ thesis, The Manchester Metropolitan University, Manchester.

10 Hernández and Bennison (2000) op. cit., p. 366. 
11 Greenland, S. (1994) 'Branch location, network strategy and the High Street'. in McGoldrick, P. and Greenland, S. (eds) 'Retailing of financial services', McGraw Hill, London, pp. 125-152.

12 Clarke, I., Bennison, D. and Pal, J. (1997) 'Towards a contemporary perspective of retail location', International Journal of Retail \& Distribution Management, Vol. 25, No. 2, pp. 59-69.

13 Hernández, T., Bennison, D. and Cornelius, S. (1998) 'The organisational context of retail locational planning', GeoJournal, Vol. 45, No. 4, pp. 295308.

14 After Hernández et al. (1998) ibid.

15 Baron, S. and Lock, A. (1995) 'The challenges of scanner data', Journal of the Operational Research Society, Vol. 46, No. 1, pp. 50-61.

16 Byrom, J. W., Hernández, T., Bennison, D. and Hooper, P. (2001) ' $\mathrm{Ex}-$ ploring the geographical dimension in loyalty card data', Marketing Intelligence E Planning, forthcoming.

17 Sleight, P. (1997) 'Targeting customers: how to use geodemographics and lifestyle data in research and marketing', 2nd edition, NTC Publications, Henley-on-Thames.

18 Hernández, T., Cornelius, S. and Bennison, D. (1995) 'Finding spatial data: An evaluation of data sources for retail location analysis', Journal of Targeting, Measurement and Analysis for Marketing, Vol. 4, No. 1, pp. 11-23.

19 Department of the Environment, (1987) 'Handling geographic information: Report of the Committee of Enquiry chaired by Lord Chorley',
HMSO, London, p. 7.

20 Moloney, T., Lea, A. C. and Kowalchuk, C. (1993) 'Manufacturing and packaged goods', in Castle, G.H. (ed.) 'Profiting from a Geographic Information System', GIS World, Fort Collins, CO, pp. 105-130.

21 Byrom et al. (2001) op. cit.

22 Newman Publishing (1999) 'Retail Directory of the UK 1999', Newman Publishing, London.

23 William Reed Publishing (1997) 'Shopping Centre \& Retail Directory 1998', 4th edition, William Reed Publishing, Crawley.

24 Hegelson, J. G. (1994) 'Receiving and responding to a mail survey: A phenomenological examination', Journal of The Market Research Society, Vol. 36, No. 4, pp. 339-347.

25 Jobber, D. and O'Reilly, D. (1996) 'Industrial mail surveys: techniques for inducing response', Marketing Intelligence \& Planning, Vol. 14, No. 1, pp. 29-34.

26 Clark, J. L. and Kaminski, P. F. (1990) 'How to get more for your money in mail surveys', Journal of Services Marketing, Vol. 4, No. 1, pp. 41-47.

27 McCormack, B. and Hill, E. (1997) 'Conducting a survey: the SPSS workbook', International Thomson Business Press, London.

28 Hague, P. (1994) 'Questionnaire design', Kogan Page, London.

29 Saunders, M. N. K., Lewis, P. and Thornhill, A. (2000) 'Research methods for business students', 2nd edition, Pearson Education, Harlow, p. 282.

30 Moloney et al. (1993) op. cit. 